\title{
Veri Zarflama Analizinde Homojen Olmayan Karar Verme Birimi Problemi için Kümeleme Analizi Yaklaşımı
}

\author{
Cluster Analysis Approach for A Non-Homogeneous DMU's Problem in DEA
}

Algın OKURSOY ${ }^{1}$, Muhsin ÖZDEMIR ${ }^{2}$

\section{ÖZET}

Veri Zarflama Analizi (VZA), doğrusal programlama modeline dayalı, parametrik olmayan bir analiz yöntemidir. VZA, benzer girdiler kullanan ve aynı tür çıktılar üreten ekonomik birimlerin göreli etkinliklerinin ölçülmesini amaçlar. VZA'da, seçilen Karar Verme Birimleri (KVB) girdiler ve çıktılar açısından benzer olmalı ve benzer çevre şartlarında faaliyet göstermelidirler. VZA karşılaştırmaya dayanan bir yöntem olduğundan, dış çevre şartlarında var olan bir değişkenlik, karar birimlerinin göreli etkinlik değerleri üzerinde belirleyici hale gelebilecektir. Bu durumda, etkinlik skorlarını etkileyebilecek olan çevresel faktörler bakımından benzer olan KVB'lerin kendi aralarında karşılaştııılması daha doğru bir yaklaşım olacaktır.

Bu çalışmada, öncelikle KVB olarak seçilen ve geniş çaplı bir coğrafi bölgede, aynı hizmet alanında faaliyet gösteren devlet hastaneleri için K-ortalamalar kümeleme analizi yardımıyla, KVB'lerin homojen alt gruplara bölünmesi amaçlanmıştır. Daha sonra, her bir küme için VZA uygulanarak, bütün KVB'lerin dâhil edildiği VZA sonuçlarıyla karşılaştırma yapılmıştır.

Anahtar Kelimeler: Veri zarflama analizi, k-ortalamalar kümeleme, etkinlik

\section{GíRiş}

Günümüzün rekabetçi dünyasında işletmeler üretim yapabilmek için kıt kaynaklarını en uygun bir biçimde değerlendirmeye her zamankinden daha fazla önem vermektedirler. Bunun için işletmeler, daha az girdi kullanarak daha fazla çıktı üretmenin yollarını aramakta ve verimliliklerini arttırmaya odaklanmaktadırlar. Bunun başarılabilmesi analitik yöntemlerin organizasyonlarda başarılı bir şekilde uygulanmasıyla mümkün olabilmektedir. Ekonomi kuramı açısından en dar anlamıyla verimlilik (productivity); üretim sürecinde boşluk olmadan, verilen bir takım girdiler ile en yüksek üretimin sağlanmasıdır. Geniş anlamda verimlilik ise, bir çıktının en az maliyetle üretilmesidir (Alpugan, 1991). Verimlilik bir işletmenin ürettiği çıktıların, bu çıktıyı elde etmek için kullandığı girdilere oranı olarak ifade edilebilir. Etkinlik (efficiency) ise; en az çaba veya maliyet ile en fazla çıkının elde edilmesidir. Bir işletme açısından ise etkinlik, amaçların ger-

\begin{abstract}
Data Envelopment Analysis (DEA) is a non-parametric method which is based on a linear programming. DEA aims at measuring relative efficiency of economic units employing similar inputs and producing the same kinds of outputs. Used Decision Making Unit (DMU) in DEA must use similar inputs/outputs and should operate under the same kind of environmental conditions. Since DEA is based on benchmarking against the best DMU, an existing variability in the external environmental conditions may affect dramatically the relative efficiency of the DMU's. In this situation, DMU's operating under the same kind of environmental conditions should be grouped into homogeneous classes according to environmental conditions having high variability. The better approach is to compare DMU's in homogeneous class with each other.

In this paper firstly, used DMU's operating over large geographical area and in the same service industry, are grouped into homogeneous classes by K-means clustering algorithm. Then, DEA is applied for each separate homogeneous group and these results are compared with the results of DEA including all DMUs.

Keywords: Data envelopment analysis, k-means clustering, efficiency
\end{abstract}

çekleştirilmesi oranı olarak tanımlanabilir (Öğüt ve Özata, 2007:71).

Verimlilik ve etkinlik analizleri için yöntemler geliştirilmiştir. Genel olarak bu yöntemler parametrik ve parametrik olmayan yöntemler olmak üzere iki başlık altında toplanabilir. Parametrik yöntemlere alternatif olarak ortaya çıkan parametrik olmayan yöntemler, çözüm tekniği olarak matematiksel programlamayı kullanır. Bu yöntemler çoklu girdi ve çoklu çıktı içerebilir. Ön hazırlık açısından ayrıntılı ve uygulaması kolaydır. Son yıllarda birden fazla girdi ile birden fazla çıktı için verimlilik ve etkinlik analizin yapılmasında en çok kullanılan teknik VZA'dır.

VZA'da sonuçların doğruluğu uygun Karar Verme Birimleri'nin (KVB) seçilmesine bağlıdır. VZA uygulamasında seçilen KVB'lerin girdiler ve çıktılar açısından benzer olması ve benzer çevre şartlarında faaliyet göstermesi gereklidir. VZA karşılaştırmaya dayanan bir yöntem olduğundan dış çevre şartlarında var ola-

${ }^{1}$ Yrd. Doç. Dr., Adnan Menderes Üniversitesi, Söke İ̧̧letme Fakültesi, Yönetim Bilişim Sistemleri Bölümü, algin.okursoy@gmail.com

${ }^{2}$ Doç. Dr., Adnan Menderes Üniversitesi, Nazilli İktisadi ve İdari Bilimler Fakültesi, İşletme Bölümü, mozdemir@adu.edu.tr 
bilecek bir değişkenlik, karar birimlerinin göreli etkinlik değerleri üzerinde belirleyici olacaktır. Bu durumda, VZA'yı uygulamadan önce etkinlik skorlarını etkileyebilecek çevresel faktörlerin belirlenmesi ve olası etkilerinin değerlendirilmesi analizin güvenirliliğini arttıracaktır.

Bu çalışmada, KVB olarak seçilen devlet hastanelerinin üzerinde etkili olabilecek olan çevresel faktörlerin etkisinin ortaya konulması amaçlanmıştır. Bu amaçla çalışmanın uygulama kısmında dört aşamadan oluşan bir süreç izlenmiştir. Birinci aşamada Kümeleme Analizi gerçekleştirerek benzer özellikler taşıyan KVB'leri aynı küme içerisinde toplanmıştır. İkinci aşamada ise, bütün KVB'leri VZA'ya dâhil ederek etkinlik skoru değerleri elde edilmiştir. Üçüncü aşamada her bir küme için ayrı ayrı VZA gerçekleştirilerek KVB'lere ait ikinci bir etkinlik skoru hesaplanmıştır. Son aşama olan dördüncü aşamada ise, ikinci aşamada etkin olmayan hastanelerden kaç tanesinin son aşamada etkin hale geldiği incelenmiş̧ir. Analizler sonucunda, etkinlik skorları ortalama değerlerinin KVB'lerin homojen gruplara ayrılmasından sonra arttığı görülmüştür. ÇaIışmada yapılan analizler için "R İstatistiksel Hesaplama ve Grafik programı" kullanılmıştır.

\section{VERi ZARFLAMA ANALIZi}

Veri Zarflama Analizi (VZA), ortak özellikler ve benzer amaçlar taşıyan birimlerin göreli etkinliklerini hesaplayan doğrusal programlamaya dayalı, parametrik olmayan bir yöntemdir (Anderson ve Williams, 1991:147). VZA, Farrell'in (1957) performans etkinliğini belirlemedeki teorik yaklaşımına dayanmaktadır (Ulucan, 2002:187). Illk kez Charnes ve arkadaşları 1978 yılında devlet okullarının verimliklerini ölçmek için kullanmışlardır. (Gencer, 2011:34) VZA, önceleri kâr amacı gütmeyen işletmelerin etkinliklerinin karşılaştırılması için kullanılırken (kamu hastaneleri, okullar vb.), daha sonraları ürün ve hizmet sektörü içerisinde faaliyet gösteren benzer işletmelerin etkinliklerinin karşılaştııılmasında da etkin bir şekilde kullanılmaya başlanmıştır(Yayar ve Çoban, 2012:168-169).

Birçok işletme, sahip oldukları sayıca çok fazla girdiyi belirli bir süreçten geçirdikten sonra çıktı üretmektedirler. VZA, bu sayıca çok olan gözlemlenmiş girdi ve çıktı değişkenlerini kullanarak, ağırlıklı çıktıların ağırlıklı girdilere oranını hesaplamakta ve buna göre her bir karar biriminin göreli etkinliğini bulmaktadır. Çok sayıda girdi ve çıktının değerlendirilmesinin zor olduğu durumlarda VZA toplam faktör verimliliği mantığı ile oldukça geçerli ve anlamlı sonuçlar vermektedir (Kutlar ve Babacan, 2008)

VZA az sayıda varsayıma sahip olduğundan birçok alanda kullanılan bir yöntemdir. Yöntemin önemli özelliklerinden birisi, parametrik yöntemlerde olduğu gibi önceden belirlenmiş herhangi bir analitik üretim fonksiyonunun varlığına gereksinim duymadan hesaplama yapabilmesidir. Parametrik ya da parametrik olmayan istatistiksel teknikler birimlerin karşılaştırılmasında ortalama bir değeri ya da ortancayı göz önüne alarak etkinsizliği kurumsallaştırırken (Yavuz, 2001:16-17) VZA, her bir birimi en iyi birim ile karşılaştırmaktadır (Uygur ve Toklu, 2004:438). Dolayısıyla, VZA yönteminde etkinlik sınırı, varsayılan bir durum değil; gerçekleşen bir gözlemdir. Etkinlik sınırı bu şekilde tespit edildiği için de, bu yöntemde rassal hata kullanılmaz (Inan, 2000:85). Bir adet girdi $\left(\mathrm{Y}_{1}\right)$ ve bir adet çıktıya $\left(\mathrm{X}_{1}\right)$ sahip olan KVB'lerine ait VZA etkin sınır eğrisi ve regresyon yöntemiyle bulunan ortalama değer fonksiyonu Şekil 1'de gösterilmektedir.

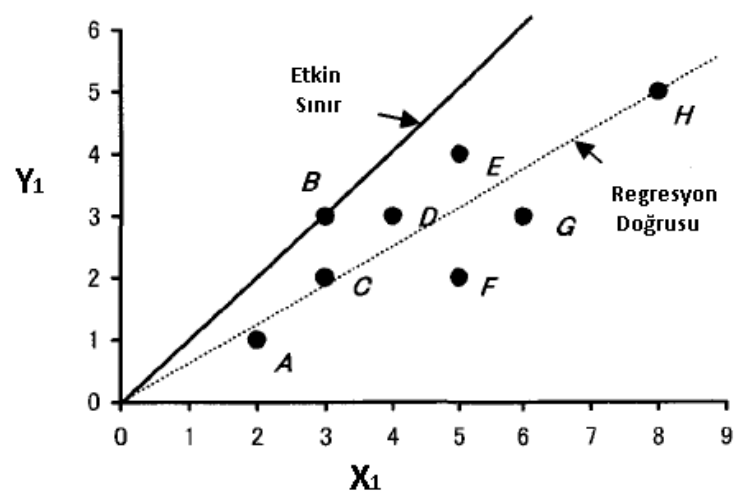

Şekil 1: Regresyon Doğrusu ve Etkin Sınır Doğrusu

( Kaynak: Cooper, Seiford ve Tone, 2006: 4)

Şekil1'de verilen her bir nokta için eğimlere bakılacak olursa $\left(\mathrm{Y}_{1} / \mathrm{X}_{1}\right)$ en yüksek eğim $B$ noktasından geçen doğruya aittir. Bu noktayı kesecek şekilde çizilecek olan doğru etkin sınır doğrusu olarak adlandırılmaktadır. Diğer noktalar ise çizilen etkin sınır doğrusunun altında kalmaktadırlar. Buna göre en az etkin birim ise F noktasıdır. Ancak, regresyon doğrusu dikkate alınarak yapılacak olan etkinlik değerlendirmesine göre, doğrunun üzerinde kalan noktalar mükemmel etkin noktalar, altında kalan noktalar ise tatminkâr olmayan noktalar olarak adlandırılmaktadır.

VZA'nın daha geniş ölçüde tanınması ve bilimsel çalışmalarda yoğun bir şekilde kullanılması VZA modelinin çeşitlenmesini getirmiş̧ir. CCR oran modeli (Charnes, Cooper ve Rhodes'un baş harflerinden oluşmaktadır), BCC (Banker, Charnes ve Rhodes) ölçeğe göre getiri modeli, toplamalı model ve çarpımlı model olmak üzere dört ana model geliştirilmiş ve kullanılmıştır. Farklı modeller uygulandığında dahi elde edilen etkinlik değerlerinin güvenilir olduğu kanıtlanmıştır.

CCR modeli, teknik etkinlik ile ölçek etkinliğinin birleşimden oluşan toplam etkinliği ölçmektedir. CCR modelini kullanarak KVB'lerin göreceli etkinliklerinin 
belirlenmesinde, analiz edilen KVB'lerin etkin kabul edilebilmesi için hem teknik etkinliğe hem de ölçek etkinliğine sahip olmaları gerekmektedir. CCR modeli, "Girdi Yönlü CCR" ve "Çıktı Yönlü CCR" olmak üzere ele alınmaktadır (Gökgöz, 2009:37). BCC modeli ise Banker, Charnes ve Cooper tarafından (1984) ölçeğe göre getiri varsayımı altında etkinliği değerlendirmek için CCR modeline $\sum_{j=1}^{m} \ddot{e}_{\mathrm{j}}=1$ kısıtı eklenerek oluşturulmuştur (Cooper ve Zhu, 2011:13).

VZA uygulamalarında değerlendirme yapılacak karar birimlerine ilişkin önemli bir dizi homojenlik varsayımları bulunmaktadır (Dyson ve Shale, 2001:245). Bu varsayımlar, aynı üretim sürecine sahip olmaları, benzer girdiler ile benzer çıtıları üretmeleri gerektiği ve aynı çevresel şartların etkisi altında olmaları şeklinde sıralanabilir (Haas ve Murphy, 2003:531). Ancak genel olarak uygulamalarda bu durumun göz ardı edildiği görülmektedir (Najadat ve Schesvold, 2005:255). Örnek olarak banka şubeleri ele alınacak olursa, büyük banka şubeleri bankacılık alanında muhtemel birçok işlemi yerine getirirken, küçük veya yerel olarak faaliyet gösteren banka şubeleri ise daha az işlem hacmine sahip olduklarından her türlü bankacılık işlemi ile meşgul olmayacaklardır. Böyle bir durumda standart VZA uygulamasıyla yapılacak olan bir karşılaştırma sağlıklı sonuçların elde edilmesine engel olacaktır (Mar, 2009:1125).

Bu çalışmada, KVB olarak seçilen hastanelerin içinde bulundukları çevre şartlarından etkilendikleri ve bu etkinin hastanelerin girdileri üzerinde heterojen bir yapı oluşturduğu üzerinde durulmaktadır. Çalışmada, KVB olarak seçilen hastanelerin bulundukları bölgenin nüfusu, gelirden aldıkları pay, eğitimli insan kaynağı gibi daha sayılabilecek pek çok faktör hastanelerin büyüklükleri üzerinde etkili olabilecektir. Bu da, VZA için önemli olan KVB'lerin homojenliği varsayımının sağlanamamasına neden olacaktır. Bu çalışmada, homojenlik sorununun üstesinden gelebilmek için KVB'ler K-Ortalama kümeleme algoritması kullanılarak homojen alt gruplara ayırılmaya çalışılmıştır. Gruplar olmadan ve gruplar için yapılan VZA sonuçları karşılaştıılarak homojenlik sağlandığında etkinlik değerlerinin nasıl değiştiği incelenmiştir.

\section{LITERATÜR TARAMASI}

Literatürde homojen olmayan KVB'lerin kullanılarak VZA'nın gerçekleştirilebilmesi için değişik yöntemler kullanılmıştır. Athanassopoulos ve Thanassoulis (1995) bira endüstrisinde yaptıkları çalışmada, KVB olarak seçilen 60 bira üreticisini incelemişler ve aralarındaki homojenliği sağlamak için KVB'leri ticari yapıya sahip olan ve olmayan şeklinde iki gruba ayır- mışlardır. Sarrico ve Dyson (2000), bir üniversitede akademik bölümlerin karşılaştırılması için yaptıkları çalışmada, fen bilimleri ve sosyal bilimler alanındaki bölümlerin sahip oldukları donanım ve laboratuvar farklılıkları nedeniyle homojen olmadıklarını belirtmişlerdir. Bu sorunun üstesinden gelebilmek için dış değerlendirme kümesi kullanmışlardır. Has ve Murphy (2003) ise, VZA'da homojenlik sorunuyla başa çıkabilmek için iki aşamalı VZA modelinin kullanılmasını önermişlerdir. Najadat, Nygard, ve Schesvold (2005) ve Po, Guh, ve Yang (2009) çalışmalarında homojenlik sorununu VZA'ya dayalı bir kümeleme yöntemi kullanarak çözmeyi amaçlamışlardır. Tarım alanlarının etkinliğinin karşılaştırılmasının amaçlandığı çalışmada Gomes, Mello, ve Freitas (2012), ilk olarak kullanılan teknoloji çeşitlerine göre KVB'leri gruplandırmışlardır. Daha sonra her bir grup için ayrı ayrı gerçekleştirilen VZA sonucunda gruplardaki etkin olan KVB'ler belirlenmiştir. Her bir grupta etkin olan KVB'leri kullanarak gerçekleştirilen diğer bir VZA sonrasında hesapladıkları ortalama etkinlik skorunu her bir grup için düzeltme faktörü şeklinde kullanarak homojenlik sorununun üstesinden gelmeye çalışmışlardır.

Literatürde VZA ile hastanelerin etkinlik skorlarının hesaplanması üzerine birçok çalışma bulunmaktadır. Yapılan çalışmaların bazıları hastanelerin mülkiyet durumlarının (finansman şekillerinin) performanslarına etki ettiğini göstermiştir (Schreyögg ve Busse, 2011; Biqrn ve Magnussen, 2003; Burgess ve Wilson, 1996). Ayrıca eğitim veren hastaneler ve eğitim vermeyen hastaneler için yapılan VZA çalışmaları, bu iki grubun etkinlik skorlarının farklı olduğunu göstermiştir (Gök ve Sezen, 2011; Groddkopf ve Valdmanis, 2001). Literatürde VZA ile hastane etkinliklerinin değerlendirilmesinde girdi değişkeni olarak yatak sayısı, pratisyen hekim sayısı, uzman hekim sayısı ve yönetim kadrosu en çok kullanılan değişkenler olarak karşımıza çıkmaktadır. Bunun yanında en çok kullanılan çıktı değişkenleri ise hasta sayısı, ameliyat sayısı, ziyaretçi sayısıdır. Bunların yanında ölüm oranları, hizmet içi eğitim saatleri, bebek ölüm oranları, kârlılık ve maliyet değerleri de çıktı değişkeni olarak kullanılabilmektedir (Gök ve Sezen, 2011:138).

\section{K-ORTALAMA KÜMELEME ANALIZi}

Kümeleme Analizi (cluster analysis), yapısal olmayan çok değişkenli analizler içinde sık kullanılan bir yöntemdir. Kümeleme analizi metodolojisi verilen bir veri setini homojen alt setler (kümeler) olarak düzenleyen algoritmalardan oluşmaktadır (Izenman, 2008). Bu çalışmada, verilerin homojen gruplara bölünmesi için K-ortalamalar kümeleme (K-means clustering) algoritması kullanıımıştır. 
En eski kümeleme algoritmalarından olan K-Ortalamalar, 1967 yılında J.B. MacQueen tarafından geliştirilmiş̧tir (MacQueen, 1967). K-ortalamalar kümeleme algoritması, eldeki verileri özelliklerine göre hiçbir sınıf bilgisi olmadan daha önceden belli bir kritere göre belirlenmiş $\mathrm{K}$ sayıda homojen kümeye bölme işlemi yapan bir algoritmadır. K-Ortalama algoritması, her verinin sadece bir kümeye ait olabilmesine izin verir. Bu nedenle, kesin bir kümeleme algoritmasıdır (Işık ve Çamurcu, 2007:32). Kümelerin benzerlikleri, bir küme içindeki nesnelerin ortalama değeri alınarak ölçülmeye çalışılır. K-Ortalama algoritmasında öncelikle birbirine en uzak olacak şekilde her bir küme için k sayıda başlangıç merkez noktası seçilir. k sayıda küme için başlangıç merkezleri belirlendikten sonra, gözlemlerin hiçbiri dışarıda kalmayacak şekilde kendilerine en yakın küme merkezi ile ilişkilendirilir. Başlangıçta belirlenen $k$ sayıda merkezin seçimine göre sonuçların değişeceği göz önünde bulundurulması gerekir. Algoritma k sayıda merkezi her seferinde daha iyi bir çözüme ulaştırmak için yeniden seçer. Bu seçimleri yaparken aşağıdaki amaç fonksiyonunun en küçük değerini bulmaya çalışır (Liu ve Yu, 2009:275).

Yukarıda verilen amaç fonksiyonu hata kareler ortalaması olarak isimlendirilmektedir. Formülde verilen j. kümeye atanan i. gözlemi, ise, j. kümeyi temsil etmektedir. Algoritma genel olarak aşaıdaki adımları takip etmektedir (Johnson ve Wichern, 2007: 696)

i. Gözlemler tarafından temsil edilen uzaya k nokta yerleştirilir.

ii. Her bir gözlem, yerleştirilen k sayıda küme merkezine göre yerleştirilir. Yerleştirmede her gözlem bir kümeye atanmalıdır.

iii. Yeni bir k sayıda küme merkezi belirlenir.

iv. i. ve ii. adıma k merkezler değişim göstermeyecek hale gelene kadar devam edilir.

Algoritmanın nihai bir sonuca ulaşacağı matematiksel olarak ispatlandıysa da, genellikle amaç fonksiyonunun değerini minimum yapacak en uygun çözümü bulmadan belirli bir tekrar sayısından sonra algoritma sonlandırılır. Algoritmanın tekrar sayısının 10'dan az olmaması istenir (Nakip, 2003: 440).

K-Ortalamalar kümeleme algoritmasında küme sayısının belirlenmesi algoritmanın en kritik noktasıdır. Küme sayısına karar verebilmek için en çok kullanılan yöntem Yamaç-Birikinti Grafiği'nin (Scree Plot) çizilmesidir. Farklı küme sayıları için grup içi hata karelerinin toplamı dikey eksende olacak şekilde çizilen grafikte, hata kareler toplamındaki önemli ölçüde azaldığı nokta k küme sayısının değeri olarak kabul edilir (Wang ve $\mathrm{Hu}, 2012: 11$ )

\section{UYGULAMA}

Çalışmanın ana kütlesini T.C. Sağlık Bakanlığı'nın 2006 yılı Yataklı Tedavi Kurumları İstatistik Yıllığı'ndaki toplam 1205 hastaneden 769 Devlet hastanesi oluşturmaktadır. Araştırmada KVB'lerin finansman bakımından ve verilen hizmetler homojenliğinin sağlaması amacıyla, tedavi hizmetleri sonrasında katkı payı talebinde bulunan özel hastaneler ve araştırma ve uygulama hastaneleri ve özel dal hastaneleri kapsam dışında bırakıımıştır. Girdi ve çıktı değişkenlerine ait değerlerin negatif ve eksik olmaması VZA'nın temel varsayımları arasında yer aldığından, hastane performanslarını değerlendirmek için seçilen girdi ve çıktı değişkenleri değerlerinden herhangi birine sahip olmayan devlet hastaneleri araştırmanın dışında tutulmuştur (Saen, 2003:146). Buna göre çalışmada kullanılan analizlere 486 devlet hastanesi dâhil edilmiştir. Araştırmada hastane performanslarının değerlendirilmesi için literatürde en sık rastlanılan girdi ve çıktı değişkenleri kullanılmıştır. Kullanılan çıktılar; poliklinik sayısı, çıkan hasta sayısı, ayarlanmış ameliyat sayısı ve yatılan gün sayısı; girdiler ise hasta yatak sayısı, uzman doktor sayısı ve pratisyen doktor sayısidır.

Uygulamada kadro ve fiili yatak olmak üzere iki tür yatak deyimi bulunmaktadır. Kadro (kontenjan) yatağı, hastaneye Bakanlık onayı ile tahsis edilen yatak sayısıdır. Fiili yatak ise belirli bir süre sonunda her ay veya bir yılsonunda hastanede hasta yatağı olarak serili (boş veya dolu) yatak sayısıdır (Sağlık Bakanlığı, 2011). Bu araştırmada kadro yatak sayısı kullanılmıştır. Yatılan Gün Sayısı, hastanın hastanede kaldığı günlerin toplamıdır. Gün sayısının hesaplanmasında hastanın giriş çıkış günlerinden yalnız girdiği gün sayılmaktadır. Hastanın çıkış günü dâhil edilmemektedir. Hastanın çıkış tarihinden giriş tarihi çıkarılarak elde edilmektedir. Aynı gün yatıp çıkan hastanın hasta günü 1 gün olarak kabul edilmektedir (Sağlık Bakanlığı, 2011). Ayarlanmış ameliyat sayısı hastanelerin yapmış oldukları büyük ameliyat sayısının tamamının, orta ameliyat sayılarının 1/3'nün ve küçük ameliyat sayılarının ise $1 / 7$ 'sinin toplamları alınarak hesaplanmıştır (Özcan ve Özgen, 2009). Bu şekilde küçük ve orta büyüklükteki ameliyatlar maliyet açısından büyük ameliyat maliyetlerine göre ayarlanmıştır (Büyükkayıkçı ve Şahin, 2000). Yataklı Tedavi Kurumları İstatistik Yıllığı'nda Çıkan Hasta sayısı bir yıl içerisinde hastaneye yatırılan hastaların şifa ya da salah hali ile evlerine veya başka kurumlara çıkarılan kişilerin sayıdır. Ölüm vakaları bu sayıya dâhil edilmemiştir. Bu çalışmada toplam çıkan hasta sayısı, hastaneden taburcu olan hastaların sayısı ile ölen hastaların sayısının toplamı olarak alınmıştır. 
Analizde kullanılacak olan girdi ve çıktı değişken grupları arasındaki istatistiksel ilişki Pearson Korelasyon katsayıları hesaplanarak araştırılmıştır. Hesaplanan korelasyon katsayılarına göre, hastane perfor- manslarını ölçmek için seçilen girdi ve çıktı değişkenleri arasında pozitif bir iliş̧kinin varlığı tespit edilmiştir. Korelasyon analizi sonuçları Tablo 1'de verilmiştir.

Tablo 1: Girdi ve Çıktı Değişkenleri Sonuçları Arasındaki Korelasyon Analizi Sonuçları

\begin{tabular}{|c|c|c|c|c|c|c|c|c|}
\hline & \multicolumn{2}{|c|}{ Poliklinik Sayısı } & \multicolumn{2}{|c|}{ Toplam Çıkan Hasta } & \multicolumn{2}{|c|}{ Yatılan Gün Sayısı } & \multicolumn{2}{c|}{ Ayarlanmış Ameliyat Sayısı } \\
\hline Girdiler & $\begin{array}{c}\text { Korelasyon } \\
\text { Katsayısı }\end{array}$ & p Değeri & $\begin{array}{c}\text { Korelasyon } \\
\text { Katsayısı }\end{array}$ & p Değeri & $\begin{array}{c}\text { Korelasyon } \\
\text { Katsayısı }\end{array}$ & p Değeri & $\begin{array}{c}\text { Korelasyon } \\
\text { Katsayısı }\end{array}$ & p Değeri \\
\hline Yatak Sayısı & 0,877 & 0,000 & 0,902 & 0,000 & 0,928 & 0,000 & 0,842 & 0,000 \\
\hline $\begin{array}{c}\text { Uzman } \\
\text { Doktor } \\
\text { Sayısı }\end{array}$ & 0,921 & 0,000 & 0,891 & 0,000 & 0,878 & 0,000 & 0,864 & 0,000 \\
\hline $\begin{array}{c}\text { Pratisyen } \\
\text { Doktor } \\
\text { Sayısı }\end{array}$ & 0,848 & 0,000 & 0,839 & 0,000 & 0,821 & 0,000 & 0,792 & 0,000 \\
\hline
\end{tabular}

Tablo 1'de görüleceği üzere girdi ve çıktı değişkenleri arasında pozitif bir korelasyon bulunmaktadır. Bu sonuçlara göre hastane girdi ve çıktılarının izotonik (eş aralıklı) olduğu doğrulanmaktadır. Diğer bir ifade ile hastane girdilerindeki her hangi bir artış hastane çıktılarının değerlerinde her hangi bir azalmaya yol açmayacağı varsayımıdır.
Türkiye'deki devlet hastanelerine bakıldığında alt yapı, çalışan sağlık personeli ve doktor sayıları açısından homojen bir yapıya sahip olmadığı görülmektedir. VZA analizinde kullanılan girdi değişkenlerinin (yatak sayısı, uzman doktor sayısı ve pratisyen doktor sayısı) araştırmada kullanılan 486 devlet hastanesi için histogramları Şekil 2'de verilmiştir.

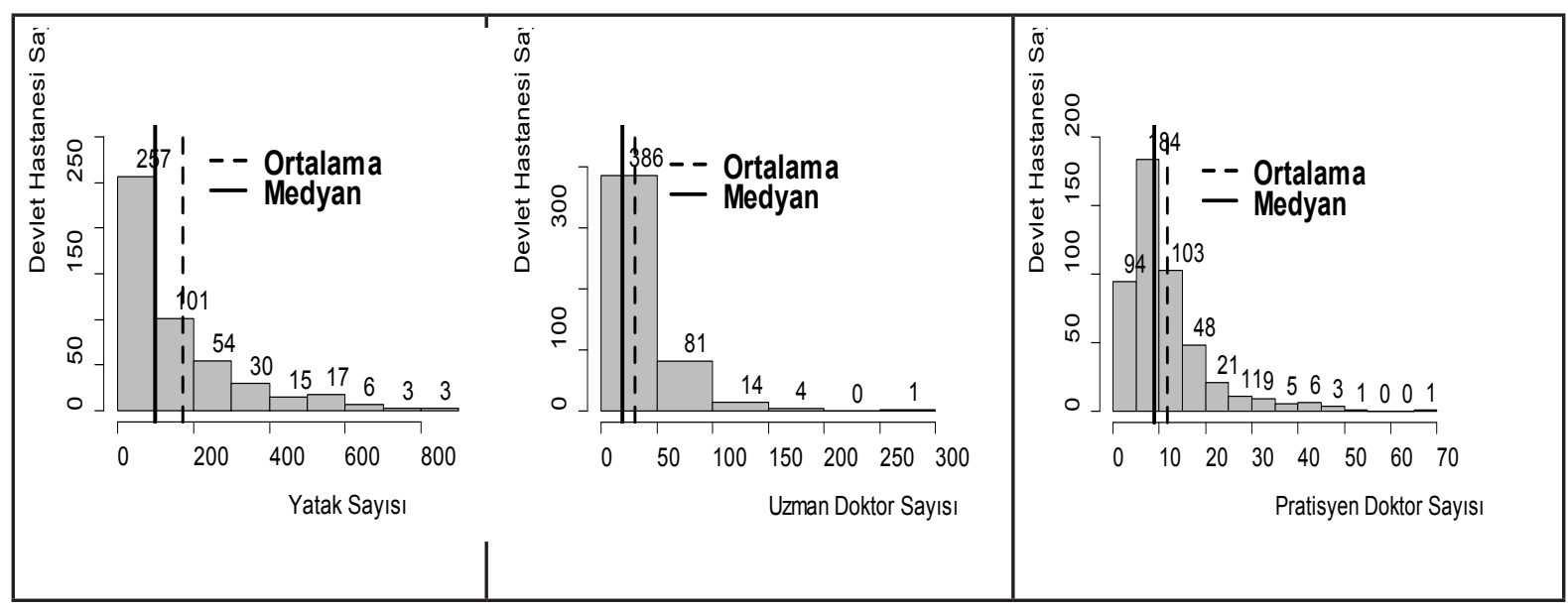

Şekil 2: VZA Analizinde Kullanılan Girdi Değişkenlerinin Histogramları

Şekil 2'de verilen histogramlara göre, 486 devlet hastanesi, kullandıkları girdi değişkenleri bakımından homojen bir yapıya sahip değillerdir. VZA'da etkinliği en yüksek olan karar birimi etkinlik sınırı olarak kabul edildiğinden, karar birimlerinin etkinliği bu en etkin karar birimine göre hesap edilmektedir. Dolayısıyla, devlet hastanelerinin homojen bir yapıda bulunmaması, etkinlik skorlarını etkileyebilecek ve etkin olmayan KVB'lerin sayııını arttıracaktır. Bunun üstesinden gelebilmek için çalışmada, analize dâhil edilen devlet hastaneleri için homojen grupların elde edilmesi amaçlanmış ve bunun için K-Ortalamalar kümeleme analizi uygulanmıştır.

\subsection{KÜMELEME ANALIZINININ UYGULANMASI}

Uygulamanın birinci aşamasında, çalışmada kullanılan girdi değişkenleri yardımıyla analize dâhil edilen 486 devlet hastanesi homojen alt gruplara ayrılmıştır. Çalışmada küme (grup) sayısını belirlemek amacıyla K-ortalamalar kümeleme algoritması farklı küme sayıları (K) için çalıştırılmıştır. Her bir K değeri için 'gruplar içi hata karelerinin toplamı' hesaplanmıştır. K-ortalamalar kümeleme algoritmasının farklı K (grup) sayısı ile karşılık gelen 'gruplar içi hata karelerinin toplamı' için çizilen Yamaç-Birikinti Grafiği Şekil 3 'te verilmektedir. 


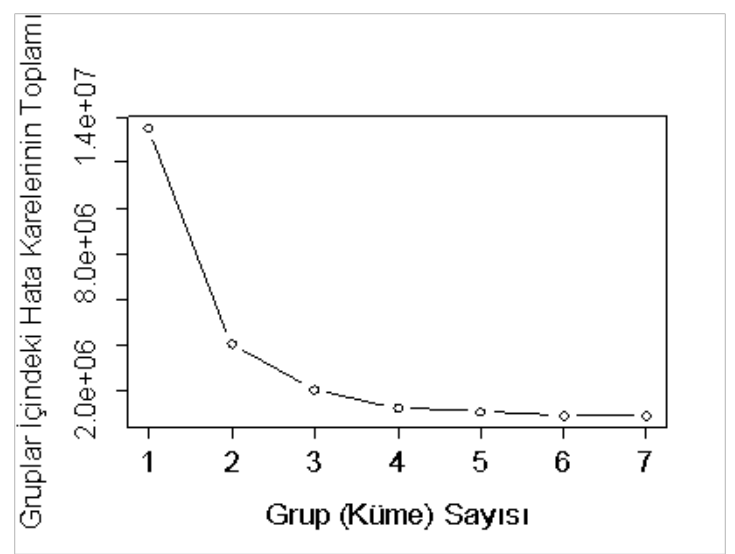

Şekil 3: K-Ortalamalar Kümeleme Algoritmasının Farklı K (Grup) Sayı ile Karşılık Gelen Gruplar İçindeki Hata Karelerinin Toplamı
Şekil 3'te görüleceği üzere K sayısı dörtten büyük olduğunda 'gruplar içindeki hata karelerinin toplamındaki azalma $\mathrm{K}=4$ 'den sonra oldukça az olmaktadır. Dolaysıyla bu çalışmada K-ortalamalar kümeleme algoritması için optimal K değeri 4 olarak belirlenmiştir. K-Ortalamalar kümeleme algoritması $\mathrm{K}=4$ değeri ile çalıştırıldığında elde edilen grupların büyüklükleri ve değişkenlere göre grup ortalamaları Tablo 2'de, yatak sayısı ve pratisyen doktor sayısına göre dağılma grafiği Şekil 4'te gösterilmiştir.

Tablo 2: K-Ortalamalar Kümeleme Algoritması K=4 Değeri ile Elde Edilen Grup Büyüklükleri ve Grup Ortalamaları

\begin{tabular}{|c|c|c|c|c|c|c|c|c|}
\hline Grup & $\begin{array}{c}\text { Grup } \\
\text { Büyüklüğü }\end{array}$ & $\begin{array}{c}\text { Poliklinik } \\
\text { Sayısı }\end{array}$ & $\begin{array}{c}\text { Toplam Çıkan } \\
\text { Hasta }\end{array}$ & $\begin{array}{c}\text { Yatılan Gün } \\
\text { Sayısı }\end{array}$ & $\begin{array}{c}\text { Ayarlanmış } \\
\text { Ameliyat } \\
\text { Sayısı }\end{array}$ & $\begin{array}{c}\text { Yatak } \\
\text { Sayısı }\end{array}$ & $\begin{array}{c}\text { Uzman } \\
\text { Doktor } \\
\text { Sayısı }\end{array}$ & $\begin{array}{c}\text { Pratisyen } \\
\text { Doktor } \\
\text { Sayısı }\end{array}$ \\
\hline 1 & 68 & 519891,06 & 13458,53 & 69005,62 & 4354,29 & 347,88 & 61,18 & 19,16 \\
\hline 2 & 121 & 323060,69 & 7239,44 & 33844,21 & 2250,00 & 181,66 & 34,64 & 12,39 \\
\hline 3 & 262 & 128674,19 & 2272,24 & 8518,97 & 427,66 & 61,55 & 10,39 & 7,09 \\
\hline 4 & 35 & 885840,34 & 27118,91 & 147587,09 & 10223,47 & 606,29 & 105,00 & 30,26 \\
\hline
\end{tabular}

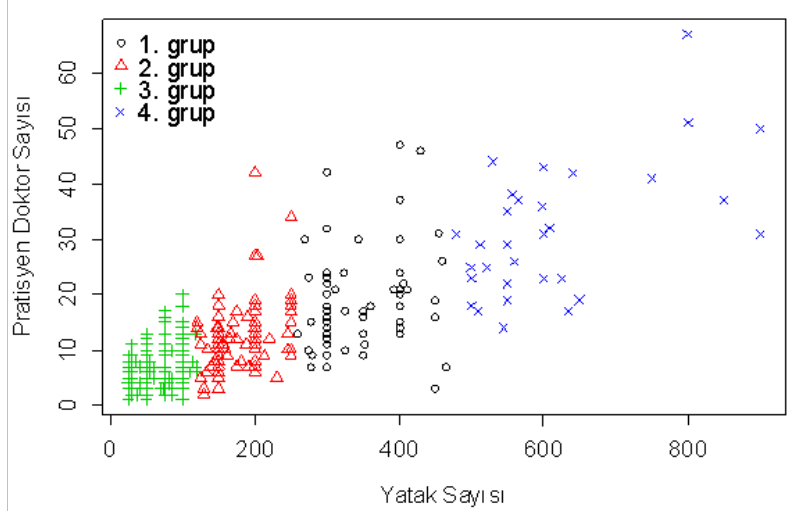

Şekil 4: 486 Devlet Hastanesinin K-Ortalamalar Kümeleme Algoritması (K=4) Gruplanması için Yatak Sayısı ve Pratisyen Doktor Sayısına Göre Serpilme Diyagramı
Kümeleme analizine göre 1. grup 68, 2. Grup 121, 3. grup 262 ve 4 . Grup 35 devlet hastanesinden oluşmaktadır. Genel olarak bakıldığında, yatak sayısı, uzman doktor sayısı ve pratisyen doktor sayısı ortalamaları en yüksek olanlar grup 4 içerisinde toplanmıştır. Grup 4'ü sırasıyla grup 1, grup 2 ve grup 3 takip etmektedir. Girdi değişkenlerine paralel olarak çıktı değişkenleri içinde aynı sıralama söz konusudur.

\subsection{VERI ZARFLAMA ANALIZININ UY- GULANMASI}

Uygulama sürecinin ikinci aşamasında 486 devlet hastanesi için VZA gerçekleştirilmiş ve göreli etkinlik skorları hesaplanmıştır. VZA modeli olarak çıktı yönlü CCR ve BCC modelleri kullanılmıştır. Girdileri sabit tutarak çıktılara göre hastanelerin etkinliğinin incelenebilmesi için bu iki model çalışmada kullanılmaktadır. Uygulanan VZA'ya göre elde edilen sonuçlar Tablo 3'te sunulmuştur. 
Tablo 3: Çalışmaya Dâhil Edilen Bütün KVB'ler için VZA Etkinlik Skorları İstatistikleri

\begin{tabular}{|c|c|c|c|c|c|}
\hline \multirow{3}{*}{$\begin{array}{r}\text { Sinırlar } \\
0-0.4999\end{array}$} & $\begin{array}{l}\text { Çıktı } \\
\text { Yönlü } \\
\text { CCR }\end{array}$ & $\begin{array}{c}\text { Çıktı Yönlü } \\
\text { BCC }\end{array}$ & & & \\
\hline & \multicolumn{2}{|c|}{ Frekanslar } & & & \\
\hline & 69 & 24 & & & \\
\hline $0.5000-0.5999$ & 96 & 60 & & Çıktı Yönlü CCR & Çıktı Yönlü BCC \\
\hline 0.6000-0.6999 & 113 & 95 & Ortalama & 0.679 & 0.765 \\
\hline 0.7000-0.7999 & 84 & 97 & Std. Sap. & 0.186 & 0.174 \\
\hline 0.8000-0.8999 & 55 & 79 & Min. & 0.028 & 0.198 \\
\hline 0.9000-0.9999 & 32 & 38 & Etkin KVB Sayısı & 37 & 93 \\
\hline 1.000 (Etkin) & 37 & 93 & Etkin KVB Yüzde & $\% 7.61$ & $\% 19.14$ \\
\hline
\end{tabular}

Tablo 3 incelendiğinde çıktı yönlü CCR modeli için 37 hastanenin (\%7.6), çıktı yönlü BCC modeli içinde 93 hastanenin (\%19.1) etkin olduğu belirlenmiştir. Her iki VZA modelinde KVB'lerin yarısından fazlası ortalama etkinlik skorunun altında değer almıştır. Çıktı yönlü VZA modelinde KVB'lerin \%14.2'sinin, çıktı yönlü BCC modelinde ise KVB'lerin \% $\%$ 'inin etkinlik skoru 0.5 ve altındadır.

Uygulama sürecinin üçüncü aşamasında daha önce K-Ortalama kümeleme analizi sonucunda elde edilen homojen grupların her birisi için ayrı ayrı VZA gerçekleştirilmiştir. Böylelikle, KVB'lerin homojen gruplara ayrıldıktan sonra hesaplanan etkinlik skorları ile ikinci aşamada hesaplanan etkinlik skorları arasındaki değişim incelenerek gruplara ayırmanın ne ölçüde faydalı olduğu tespit edilebilecektir. Her bir grup için yapılan VZA sonucunda etkin olan ve olmayan KVB sayıları Tablo 4'te verilmektedir.

Tablo 4: Kümeleme Analizi Sonucunda Elde Edilen Gruplar için VZA'ya Göre Etkin Olan ve Olmayan Hastane Sayıları

Çıktı Yönlü CCR

\begin{tabular}{|c|c|c|c|c|}
\hline Gruplar & Etkin & $\begin{array}{c}\text { Etkin } \\
\text { Olmayan }\end{array}$ & $\begin{array}{c}\text { Etkin Olan } \\
\text { Yüzde }\end{array}$ & Toplam \\
\hline Grup1 & 11 & 57 & $16,18 \%$ & 68 \\
\hline Grup2 & 25 & 96 & $20,66 \%$ & 121 \\
\hline Grup3 & 28 & 234 & $10,69 \%$ & 262 \\
\hline Grup4 & 14 & 21 & $40,00 \%$ & 35 \\
\hline
\end{tabular}

Kümeleme analizi sonucunda elde edilen gruplar için yapılan VZA'da çıktı yönlü CCR için en yüksek etkinlik yüzdesi toplam 21 hastaneyi içeren grup 4'e aittir. En düşük etkinlik yüzdesi ise 262 hastaneyi içeren grup 3'e aittir. Çıktı yönlü BCC modeline göre yapılan VZA'da ise, en yüksek etkinlik yüzdesi yine 35 hastaneyi içeren grup 4'e aittir. En düşük etkinlik yüzdesi ise yine benzer şekilde grup 3'e aittir.

VZA'da seçilen KVB'lerin aynı çevresel şartlarda faaliyet göstermesi analiz sonuçlarının doğruluğu bakımından önemli bir kısıt olarak karşımıza çıkmaktadır. Bu çalışmada KVB olarak devlet hastaneleri seçilmiştir. Hastaneler bir sistem yaklaşımı içinde ele alınıp tanımlanabilen organizasyonlardır. Buna göre hastaneler; dinamik, değişken bir çevre içinde, aldıkları girdileri dönüştürme süreçlerinden geçirerek,
Çıktı Yönlü BCC

\begin{tabular}{|c|c|c|c|c|}
\hline Gruplar & Etkin & $\begin{array}{c}\text { Etkin } \\
\text { Olmayan }\end{array}$ & $\begin{array}{c}\text { Etkin } \\
\text { Olan } \\
\text { Yüzde }\end{array}$ & Toplam \\
\hline Grup1 & 23 & 45 & $33,82 \%$ & 68 \\
\hline Grup2 & 44 & 77 & $36,36 \%$ & 121 \\
\hline Grup3 & 64 & 198 & $24,43 \%$ & 262 \\
\hline Grup4 & 22 & 13 & $62,86 \%$ & 35 \\
\hline
\end{tabular}

çıktılarının önemli bir kısmını yine aynı çevreye veren, geribildirim mekanizmasına sahip sistemlerdir (Çatalca, 2003). Bu nedenle, hastaneler çevreleriyle sürekli alış veriş içerisindedirler. Bu etkileşim neticesinde, hastanelerin elde ettikleri performans çıktıları bulundukları çevresel şartlardan etkilenecektir. Bu çevresel şartların başında, bireylerin sağlığını etkileyen sosyal faktörler gelmektedir (Okursoy, 2010). Bu çalışmada, KVB olarak seçilen devlet hastaneleri K-Ortalamalar kümeleme algoritmasıyla gruplara ayrılarak, sahip oldukları çevresel faktörlerden kaynaklı etkilerin ortadan kaldırılması amaçlanmıştır.

Uygulama sürecinin ikinci aşamasında gerçekleştirilen VZA'da etkin değilken, kümeleme analizi sonucunda homojen gruplara ayrılan KVB'lerden kaç tanesinin etkin hale geleceğinin değerlendirilmesi, homo- 
jenliğin sağlanıp sağlanmadığının anlaşılabilmesi için önemlidir. Ayrıca sonuçların değerlendirilebilmesi açısından, her bir grup için hesaplanan ortalama etkinlik skoru değeriyle, bu gruplarda yer alan KVB'lerin uygulamanın ikinci aşamasında gerçekleştirilen
VZA'da elde ettikleri etkinlik skorlarının ortalamaları karşılaştırılmıştır. Tablo 5'te her bir grup için ortalama etkinlik skorları, standart sapmaları ve ikinci aşamada etkin değilken gruplarda etkin hale gelen KVB sayıları verilmektedir.

Tablo 5: Gruplar için VZA Etkinlik Skorları Istatistikleri

\begin{tabular}{|c|c|c|c|c|c|c|c|c|c|}
\hline & & \multicolumn{4}{|c|}{ CCR } & \multicolumn{4}{|c|}{$\mathrm{BCC}$} \\
\hline & & Grup1 & Grup2 & Grup3 & Grup4 & Grup1 & Grup2 & Grup3 & Grup4 \\
\hline \multirow{3}{*}{$\begin{array}{c}\text { Gruplar için } \\
\text { VZA }\end{array}$} & Ortalama & 0,801 & 0,808 & 0,675 & 0,905 & 0,926 & 0,883 & 0,788 & 0,962 \\
\hline & Std. Sap. & 0,164 & 0,164 & 0,204 & 0,104 & 0,087 & 0,121 & 0,169 & 0,058 \\
\hline & Min & 0,170 & 0,279 & 0,028 & 0,673 & 0,607 & 0,506 & 0,224 & 0,796 \\
\hline \multirow{4}{*}{$\begin{array}{l}\text { Bütün } \\
\text { Hastaneler için } \\
\text { VZA }\end{array}$} & Ortalama & 0,678 & 0,692 & 0,660 & 0,783 & 0,731 & 0,727 & 0,776 & 0,878 \\
\hline & Std. Sap. & 0,160 & 0,169 & 0,201 & 0,132 & 0,174 & 0,179 & 0,168 & 0,131 \\
\hline & Min & 0,139 & 0,159 & 0,028 & 0,556 & 0,204 & 0,198 & 0,224 & 0,599 \\
\hline & $\begin{array}{l}\text { Etkine } \\
\text { Dönüşen }\end{array}$ & 11 & 25 & 28 & 14 & 23 & 44 & 64 & 22 \\
\hline
\end{tabular}

Bütün gruplar için ayrı ayrı yapılan her iki model için hesaplanan VZA sonuçlarına göre KVB'lere ait ortalama etkinlik skorlarının, uygulamanın ikinci aşamasında gerçekleştirilen VZA'da elde edilen ortalama etkinlik skorlarından daha yüksek değerlere sahip oldukları görülmektedir. Bunun yanında, Grup1 içerisinde yer alan 11 hastane, birinci aşamada gerçekleştirilen çıktı yönlü CCR modeline göre yapılan VZA'ya göre etkin değilken, homojen gruplar oluşturulduktan sonra etkin hale gelmiştir. Bu rakam benzer şekilde Grup2'de 25, Grup3'te 28 ve Grup4'te 14 hastane olarak Tablo 5 'te görülmektedir. Çıktı yönlü BCC modeline göre ise, Grup1'de 23, Grup2'de 44, Grup3'te 64 ve Grup4'te 22 ikinci aşamada gerçekleştirilen VZA'da etkin değilken, gruplara ayrıldıktan sonra gerçekleştirilen VZA'ya göre etkin hale gelmişlerdir.

Çalışmada KVB olarak seçilen hastaneler için homojen gruplar elde edildikten sonra her bir grup için ayrı ayrı ve gruplar oluşturulmadan bütün hastaneler için olmak üzere iki farklı VZA gerçekleştirilmiştir. Bulunan sonuçlara göre, kümeleme analizi sonrasında hastaneler arasında homojenliğin sağlanmasının VZA sonuçları üzerinde etkisi olduğu görülmektedir. Bütün KVB'lerin gruplara ayrılması her bir grup için referans hastane kümelerini değiştirdiğinden bu farklılık meydana gelmektedir. Böylelikle her bir hastane grubu için daha makul karşılaştırılabilir ölçekte referans kümeleri belirlenebilmektedir.

\section{SONUÇ}

Benzer girdileri kullanarak, aynı tür çıktıları üreten ekonomik birimlerinin göreli etkinliklerinin ölçülmesini amaçlayan VZA'da, seçilen KVB'ler girdiler ve çıktılar açısından benzer olmalı ve benzer çevre şartlarında faaliyet göstermelidirler. Ancak, literatürde yer alan VZA uygu- lamalarında homojen KVB zorunluluğunun çoğunlukla sağlanamadığı görülmektedir. Genellikle, KVB'lerin bulunduğu çevresel ve sosyo-ekonomik koşullar etkinlik değerlerine doğrudan veya dolaylı olarak etki edebilmektedir. Böylelikle KVB'ler arasında var olan bu heterojen yapı VZA sonuçlarını da etkilemektedir. Bu sorunun üstesinden gelebilmek literatürde, dış değerlendirme kümesi oluşturma, KVB'lerisahip oldukları alt yapı ya da teknolojik özelliklerine göre gruplama, iki aşamalı VZA ve düzeltme faktörü kullanılması gibi yöntemler önerilmiştir.

Bu çalışmada homojen olmayan KVB'lerin, VZA sonuçlarına etkisinin azaltılabilmesi için benzer özelliklere sahip birimler K-Ortalamalar kümeleme analizi kullanılarak homojen gruplara ayrılmıştır. Böylelikle, KVB olarak seçilen çok büyük ölçekli ile çok küçük ölçekli devlet hastanesi için göreli etkinlik skorları hesaplanırken aynı referans kümesi kullanılmamaktadır. Kümeleme analizi sonucunda, KVB'lerin VZA sonucunda kendi kümelerinde elde ettikleri göreli etkinlik skorlarının, bütün hastaneler dâhil edilerek gerçekleştirilen VZA'da elde ettikleri göreli etkinlik skorundan yüksek olduğu tespit edilmiş̧ir. Ayrıca, homojen alt gruplar için yapılan VZA'ya göre hesaplanan etkinlik yüzdesi bütün KVB'lerin dâhil edildiği VZA'ya göre daha yüksektir. Sonuç olarak VZA uygulanmadan önce, KVB'lerin kümeleme analizi kullanılarak homojen alt gruplara ayrılması, hesaplanan göreli etkinlik skorlarının daha güvenilir olarak elde edilmesini sağlamaktadır. Böylelikle bir KVB kendine benzer diğer bir KVB ile karşılaştırılabilmektedir. Bulunan sonuçlar, hastanelerin mülkiyetine, eğitim verme durumuna ve kâr amacı olup olmamasına göre ayrı değerlendirilen çalışmalara paralel olarak, bulunduğu çevresel ve sosyo-ekonomik koşulların da dikkate alınmasını göstermektedir. 


\section{KAYNAKLAR}

Alpugan, A. (1991) "Hastanelerde Verimlilik Sorunu" I. Verimlilik Kongresi, Ankara, MPM Yayınları 454.

Alsabti, K., Ranka, S. ve Singh, V. (1998) "An Efficient K-Means Clustering Algorithm” Proceedings of IPPS/SPDP Workshop on High Performance Data Mining.

Anderson, D., Sweeney, D. ve Williams, T. (1991) An Introduction to Management Science: Qantitative Approach to Decision Making, USA, West Publishing Company.

Athanassopoulos, A. ve Thanassoulis, E. (1995) "Separating Market Efficiency from Profitability and Its Implications for Planning" The Journal of the Operational Research Society, 46(1): 20-34.

Baysal, E.M., Uygur, M. ve Toklu, B. (2004) "Veri Zarflama Analizi İle TCDD Limanlarında Bir Etkinlik Ölçümü Çalışması" Gazi Üniv. Müh. Mim. Fak. Der, 19(4):437-442.

Biqrn, E., Hagen, T., Iversen, T. ve Magnussen, J. (2003) "The Effect of Activity-Based Financing on Hospital Efficiency: A Panel Data Analysis of DEA Efficiency Scores 1992-2000" Health Care Management Science, 6(4): 271-283.

Burgess, J. ve Wilson, P. (1996) "Hospital Ownership and Technical Inefficiency" Institute for Operational Research and Management Sciences, 42(1):110-123.

Büyükkayıkçı, H. ve Şahin, İ. (2000) “SSK Ulus Devlet Hastanesi Cerrahi Servisinde Hasta Maliyetlerinin Sağlık Bakanlığı Fiyat Tarifesi İle Karşılaştırması" Hacettepe Să̆lık İdaresi Dergisi, 5(3):119-148.

Cooper, W., Seiford, L. ve Tone, K. (2006) Data Envelopment Analysis: A Comprehensive Text with Models Applications, References and DEA-Solver Software, USA, Springer.

Cooper, W., Seiford, L. ve Zhu, J. (2011) "Handbook on Data Envelopment Analysis History, Models and Interpretations" International Series in Operations Research \& Management Science, 164:1-39.

Çatalca, H. (2003) Sağlık Hizmetlerinde Toplam Kalite Yönetimi, İstanbul, Beta Basım A.Ş.

Dyson, R., Allen, R., Camanho, A., Podinovski, V., Sarrico, C. ve Shale, E. (2001) "Pitfalls and Protocols in DEA" European Journal of Operational Research, (132):245-259.

Gencer, H. (2011) “IMMKB'de İşlem Gören Çimento Şirketlerinin Performanslarının Ölçülmesinde Veri Zarflama Analizi Yaklaşımı" Atatürk Üniversitesi İktisadi ve Ídari Bilimler Dergisi, 25(3-4):31-44.
Gomes, E., Mello, J. ve Freitas, A. (2012) “ Efficiency Measures For A Non-Homogeneous Group of Family Farmers" Pesquisa Operacional, 32(3):561-574.

Gök, M. ve Sezen, B. (2011) "Analyzing The Efficiencies of Hospitals: An Application of Data Envelopment Analysi" Journal of Global Strategic Management, 5(2):137-146.

Gök, Ş. ve Sezen, B. (2011) "Capacity Inefficiencies of Teaching and Non-Teaching Hospitals" The Service Industries Journal, 32(14):2307-2328.

Gökgöz, F. (2009) "Veri Zarflama Analizi ve Finans Alanına Uygulanması" Ankara Üniversitesi Siyasal Bilgiler Fakültesi Yayın No:597.

Groddkopf, S., Margaritis, D. ve Valdmanis, V. (2001) "Comparing Teaching and Non-teaching Hospitals:A Frontier Approach (Teaching vs. Non-teaching Hospitals)" Health Care Management Science, 4(2):83-90.

Güleş, H.K., Öğüt, A. ve Özata, M. (2007) "Sağlık İşletmelerinde Örgütsel Etkinliğin Artırılmasına Yönelik Veri Zarflama Analizine Dayalı Bir Uygulama” Türkiye Sosyal Araştırmalar Dergisi, (1):69-82.

Haas, D. ve Murphy, F. (2003) "Compensating For Non-Homogeneity İn Decision-Making Units in Data Envelopment Analysis European" Journal of Operational Research, (144):530-544.

İnan, E. (2000) "Banka Etkinliğinin Ölçülmesi ve Düşük Enflasyon Sürecinde Bankacılıkta Etkinlik” Bankacılar Dergisi, (34):82-96.

Işık, M. ve Çamurcu, A. (2007) "K-Means, K-Medoıds Ve Bulanık C-Means Algoritmalarının Uygulamalı Olarak Performanslarının Tespiti” İstanbul Ticaret Üniversitesi Fen Bilimleri Dergisi, 6(11):31-45.

Izenman, A. (2008) Modern Multivariate Statistical Techniques, USA, Springer.

Johnson, R.A. ve Wichern, D.W. (2007) Applied Multivariate Statistical Analysis, USA, Pearson.

Karahan, A.ve Özgür, E. (2009) Hastanelerde Performans Yönetim Sistemi Ve Veri Zarflama Analizi, Ankara, Nobel Yayın Dağıtım.

Kutlar, A. ve Babacan, A. (2008) “Türkiye'deki Kamu Üniversitelerinde CCR Etkinliği-Ölçek Etkinliği Analizi: DEA Tekniği Uygulaması" Kocaeli Üniversitesi Sosyal Bilimler Enstitüsü Dergisi, (15):148-172.

Liu, H. ve Yu, X. (2009) "Application Research of k-means Clustering Algorithm in Image Retrieval System" Proceedings of the Second Symposium International Computer Science and Computational Technology, Huangshan. 
MacQueen, J.B. (1967) "MacQueen, Some Methods for Classification and Analysis of Multivariate Observations" Berkeley Symposium on Mathematical Statistics and Probability, Statistics, Berkeley.

Mar, C. (2009) "Specialization Versus Diversification: Non-Homogeneity in Data Envelopment Analysis" 3rd International Conference on Industrial Engineering and Industrial Management, Barcelona.

Najadat, H., Nygard, K. ve Schesvold, D. (2005) "Clustering-Based Method for Data Envelopment Analysis" Proceeding og The 2005 International Conference on Modeling, Simulation and Visualization Methods.

Nakip, M. (2003) Pazarlama Araştırmalart:Teknikler ve (SPSS Destekli) Uygulamalar, Ankara, Seçkin Yayıncılık.

Okursoy, A. (2010) “Türkiye'de sağlik sistemi ve kamu hastanelerinin performanslarının değerlendirilmesi” Yayımlanmamış Doktora Tezi, Aydın, ADÜ Sosyal Bilimler Enstitüsü.

Po, R.W., Guh, Y.Y. ve Yang, M.S. (2009) "A New Clustering Approach Using Data Envelopment Analysis" European Journal of Operational Research, (199):276-284.

Saen, F.R. (2003) "A New Approach for Selecting Slightly Non-homogeneous Vendors" Journal of Advances in Management Research, 6(2):144-153.

Sağlık Bakanlığı. (2011) "Yataklı Tedavi Kurumlar1 İşletme Yönetmeliği" http://www.saglik.gov.tr/TR/ dosya/1-71966/h/yataklitedavikurumlariisletmeyonetmeligi.doc, (15.08.2011)
Sarrico, C. ve Dyson, R. (2000) "Using DEA for Planning in UK Universities-An Institutional Perspective" The Journal of the Operational Research Society, 51(7):789-800.

Surianoa, S., Wang, H. ve Hu, J. (2012) “Sequential Monitoring of Surface Spatial Variation in Automotive Machining Processes Based on High Definition Metrology" Journal of Manufacturing Systems, (31):8-14.

Şahin, İ., Özcan, Y. ve Özgen, H. (2009) “Assessment of Hospital Efficiency Under Health Transformation Program in Turkey" Central European Journal of Operations Research, 19(1):19-37.

Tiemann, O., Schreyögg, J. ve Busse, R. (2011) "Hospital Ownership and Efficiency: A Review of Studies With Particular Focus on Germany" Health Policy, 104(2):163-171.

Ulucan, A. (2002) “ISO 500 Şirketlerinin Etkinliklerinin Ölçülmesinde Veri Zarflama Analizi: Farklı Girdi Çıktı Bileşenleri ve Ölçeğe Göre Getiri Yaklaşımları ile Değerlendirmeler" Ankara Üniversitesi Siyasal Bilgiler Fakültesi Dergisi, 57(2):185-202.

Yavuz, İ. (2001) Sağlık Sektöründe Etkinlik Ölçümü (Veri Zarflama Analizine Dayalı Bir Uygulama, Ankara, Milli Prodüktivite Merkezi.

Yayar, R. ve Çoban, M. (2012) "İSO 500 Firmalar1nın Etkinliklerinin Ölçülmesinde Veri Zarflama Analizi Yaklaşımı: Dokuma Ve Giyim Eşya Sanayi” Niğde Üniversitesi İIBF Dergisi, 5(2):165-180. 